\title{
Perancangan Sistem Informasi Pengelolaan Zakat Fitrah pada Badan Amil Zakat Masjid Miftahul Jannah Kelurahan Malasilen Berbasis J2SE (Java Platform Standard Edition)
}

\author{
Muhammad Rahmatul Fauzi ${ }^{1}$, Matahari $^{2}$, Indri Anugrah Ramadhani ${ }^{3}$ \\ Prodi Pendidikan Teknologi Informasi \\ Universitas Pendidikan Muhammadiyah Sorong \\ fauzifamz19@gmail.com ${ }^{1}, \underline{\text { mataharitarie@gmail.com }}{ }^{2}, \underline{\text { indianugrah18@gmail.com }}$
}

\begin{abstract}
Abstrak: Penelitian ini bertujuan untuk menghasilkan sebuah sistem pengelolaan zakat fitrah guna memudahkan dalam pengelolaannya baik menghitung zakat fitrah berupa uang, seputar fiqih zakat fitrah dan penyimpanan data Mustahiq dan Muzakki berbasis J2SE (Java Platfrom Standard Edition). Penelitian dan perancangan sistem pada penelitian ini menggunakan teknik R\&D (Research and Development) guna membangn sebuah sistem sesuai kebutuhan pengguna. Dalam menguji sistem peneliti menggunakan Black Box yang diujicobakan oleh validator ahli dan ujicoba skala besar sebanyak 30 responden penilaian dengan presentase 88\% untuk aspek tampilan, 89\% untuk aspek penggunaan sehingga sistem dapat digunakan. Penelitian ini menghasilkan sebuah sistem informasi pengelolaan zakat fitrah berbasis J2SE (Java Platfrom Standard Edition) dan buku panduan dalam penggunaan sistem dengan presentase $86 \%$ dari hasil ujicoba kelompok besar.
\end{abstract}

Kata Kunci: Perancangan; Zakat Fitrah; J2SE, Database; Mustahiq; Muzakki

\section{Pendahuluan}

Perkembangan teknologi yang begitu pesat ditengah-tengah masyarakat sangat mempengaruhi kehidupan manusia di era modern ini terutama pada era industri 4.0. Penggunaan komputer sebagai alat bantu dalam menyelesaikan pekerjaan semakin diminati oleh berbagai kalangan, baik sebagai pengelola data ataupun proses-proses khusus dalam kehidupan sehari-hari, karena memiliki tingkat ketelitian yang tinggi dan proses kerja yang cepat. Dengan menggunakan aplikasi khususnya yang membahas pembayaran dan pengelolaan zakat juga ikut berkembang, dengan diikuti perkembangan teknologi komputer maka pengelolaan zakat fitrah akan lebih memudahkan dalam pelayanan dan penyaluran zakat fitrah.

Pengelolaan zakat adalah kegiatan perencanaan, pelaksanaan, dan pengoordinasian dalam pengumpulan, pendistribusian, dan pendayagunaan zakat. Zakat sendiri artinya adalah harta yang wajib dikeluarkan oleh seorang muslim atau badan usaha untuk diberikan kepada yang berhak menerimanya sesuai dengan syariat Islam. Dalam syariat islam ada beberapa jenis zakat salah satunya Zakat Fitrah yang wajib bagi setiap muslim dikelurkan Zakatnya ketika bulan Ramadhan.

Badan Amil Zakat pada Masjid Miftahul Jannah Kelurahan Malasilen selalu dibentuk setiap menjelang bulan Ramadhan. Badan amil zakat dibentuk untuk memudahkan masyarakat muslim di kelurahan malasilen dan sekitarnya untuk menyalurkan zakatnya sekaligus membagikan kepada yang berhak menerimanya. Badan amil zakat umumnya terbagi menjadi beberapa bidang di antaranya ketua, wakil ketua, 
pengumpulan, pendistribusian, perencanaan keuangan juga pelaporan dan administrasi semua itu dibentuk guna memudahkan kinerja dari badan amil zakat.

Bidang perencanaan juga pelaporan dan administrasi bertugas menghitung jumlah zakat yang harus dikeluarkan setiap orang berupa uang dan mendata muzakki dan yang akan menerima zakat. Dalam proses penghitungan dilakuakan dengan cara manual dan perhitungan manual tersebut terkadang terjadi kesalahan baik dari penjumlahannya ataupun penulisannya karena perhitungannya cukup kompleks. Pehitungan zakat pada umumnya dibagi menjadi 3 golongan yaitu golongan I (Besar), golongan II (Sedang) dan golongan (III) yang sesuai dengan harga beras yang dikonsumsi sehari-hari namun selalu ada perubahan besaran zakat fitrah berupa uang yang disesuaikan dengan harga bahan makanan pokok pada saat itu. Begitupun dengan administrasi yang hanya dituliskan di sebuah kertas atau hardcocpy sehingga sering terjadi hilang data-data penyalur zakat dan orang-orang yang akan menerima zakat. Setiap tahunnya data-data tersebut harus dibuat kembali karena hanya disimpan di kertas sehingga memperlambat kerja badan amil zakat dengan mendata ulang orang-orang yang menerima zakat setiap tahunnya.

Bidang pengumpulan yang bertugas menerima langsung zakat dari muzakki untuk di salurkan ke yang berhak menerima juga sering mengalami permasalahan terutama ketika muzakki menanyakan seputar fiqih zakat fiitrah karena kurangnya pengetahuan tentang fiqih zakat sehingga tidak dapat menjawab beberapa pertanyaan dari muzakki. Pertanyaan yang di tanyakan muzakki ke pada bidang pengumpulan sebenarnya bertujuan untuk mengetahuai hukum fiqih zakat sehingga muzakki paham dan tau jumlah zakat yang harus ia keluarkan. Disamping menerima dan menjelaskan tentang zakat juga bagian pengumpulan juga bertugas memberikan doa kepada muzakki atas zakat yang dikeluarkan begitupun sebaliknya, doa yang diberikan muzakki kepada sang pemberi zakat.

Untuk mengatasi permaslahan di atas maka perlu dibuatkan sistem kalkulator zakat, menu fiqih zakat dan doa-doa untuk muzakki yang dapat digunakan oleh badan amil zakat di Masjid Miftahul Jannah. Berdasarkan latar belakang tersebut, peneliti melakukan penelitian guna mengembangkan dan merancang sistem informasi pengelolaan zakat fitrah agar dapat memudahkan Badan Amil Zakat pada Masjid Miftahul Jannah Kelurahan Malasilen menyelenggarakan pengelolaan zakat tiap tahunnya.

\section{Metode Penelitian}

Penelitian ini merupakan penelitian perancangan perangkat lunak yang bertujuan untuk membangun sistem kalkulator zakat fitrah yang awalnya dalam menghitung zakat secara manual dan proses pendataan muzakki dilakukan secara konfesional atau berupa hardcocpy yang ditulis disebuah kertas atau buku. Perancangan sistem ini bertutujuan mempermudah Badan Amil Zakat Masjid Miftahul Jannah dapat lebih mudah dalam menghitung dan menyimpan data muzakki dengan aman.

Model penelitian ini menggunakan pendekatan R\&D (Research and Development) untuk melakukan tahapan penelitian agar berjalan sesuai tujuan peneliti.Penelitian R\&D adalah aktivitas riset dasar untuk mendapatkan informasi kebutuhan pengguna (needs assessment), kemudian dilanjutkan kegiatan pengembangan (development) untuk menghasilkan produk dan menguji keefektifan produl tersebut. 
(Ruyani et al., 2017) Adapun penelitian menggunakan metode R\&D ini memiliki beberapa tahapan yang bisa dilihat pada Gambar.1.

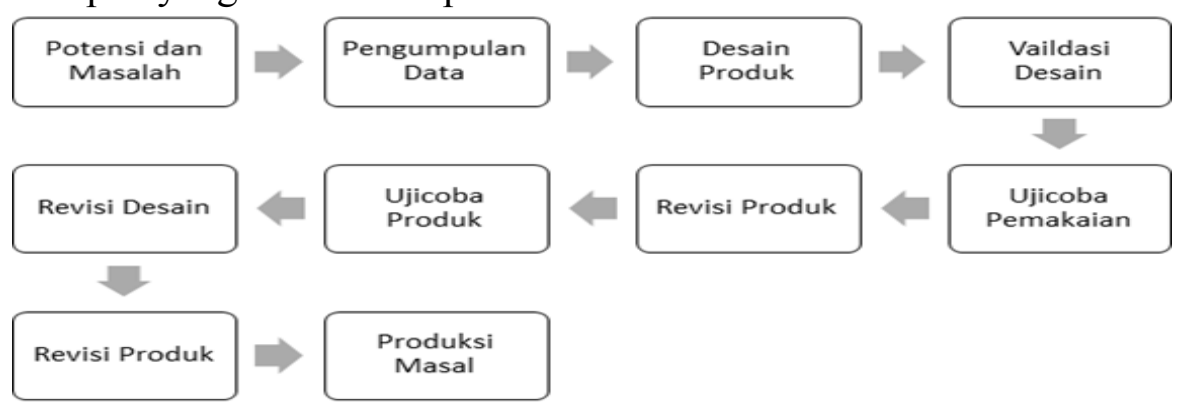

Gambar.1 Tahapan R\&D (Hanafi, 2017)

\section{Hasil dan Pembahasan}

Hasil perancangan aplikasi informasi pengelolaan zakat fitrah berbasis J2SE dengan menggunakan aplikasi NetBeans IDE 8.2 dan XAMPP menghasilkan aplikasi yang berjalan sesuai dengan rancangan aplikasi yang telah dibuat. Aplikasi Pengelolaan Zakat Fitrah memiliki 5 navigasi pada menu utamanya, yaitu : Kalkulator Zakat Fitrah, Fiqih Zakat Fitrah, Data Mustahiq, Data Muzakki, dan Do'a. Alur navigasi aplikasi Pengelolaan Zakat Fitrah dapat dilihat pada Gambar.2.

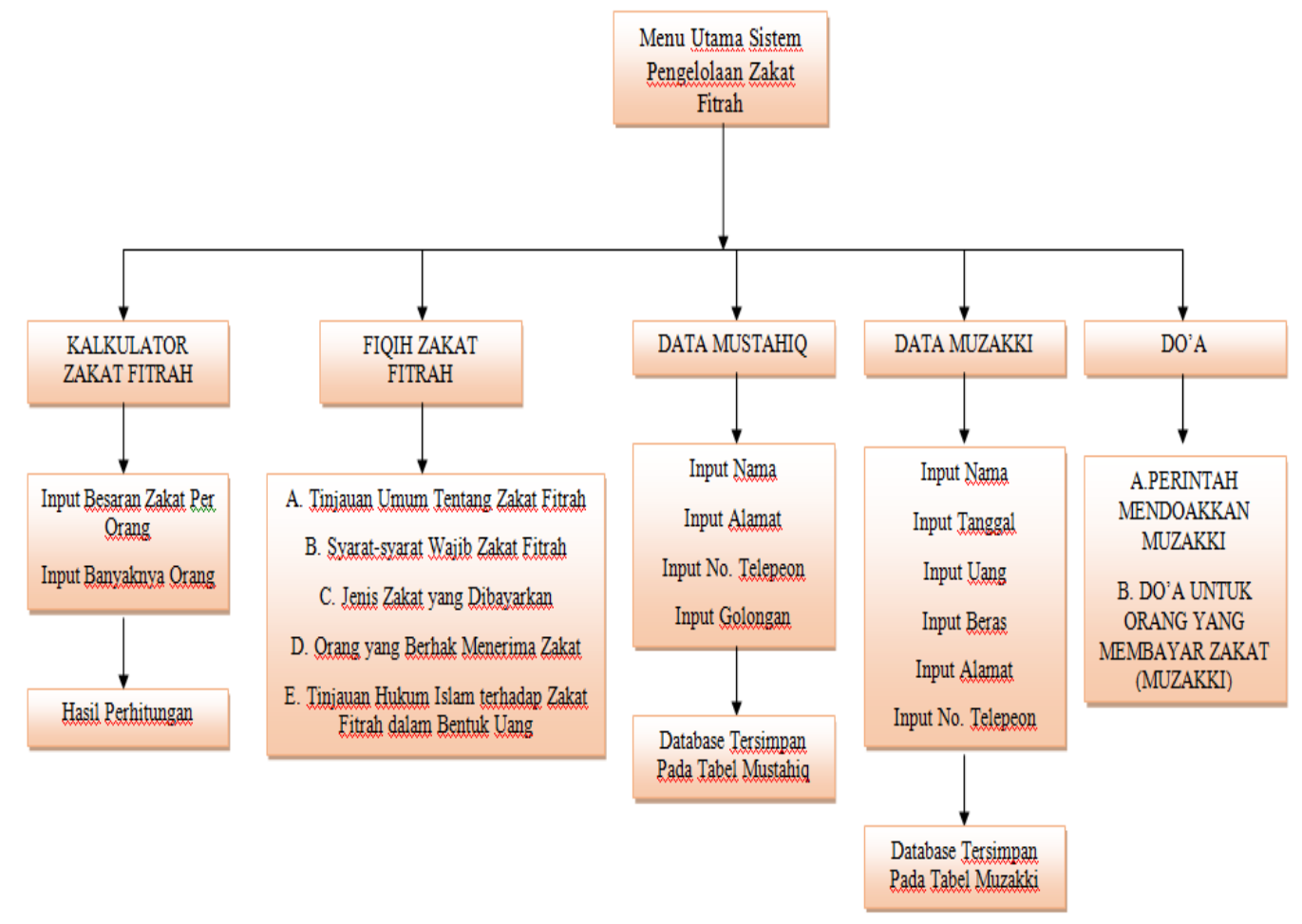

Gambar.2 Alur Navigasi Aplikasi Pengelolaan Zakat Fitrah

Tampilan menu utama sistem pengelolaan Zakat Fitrah BAZ Masjid Miftahul Jannah Kelurahan Malasilen seperti pada Gambar.3 terdiri dari 5 menu yaitu Kalkulator Zakat fitrah, Fiqih Zakat Fitrah, Data Mustahiq, Data Muzakki, dan Do'a yang dapat dilihat pada Gambar 3. 


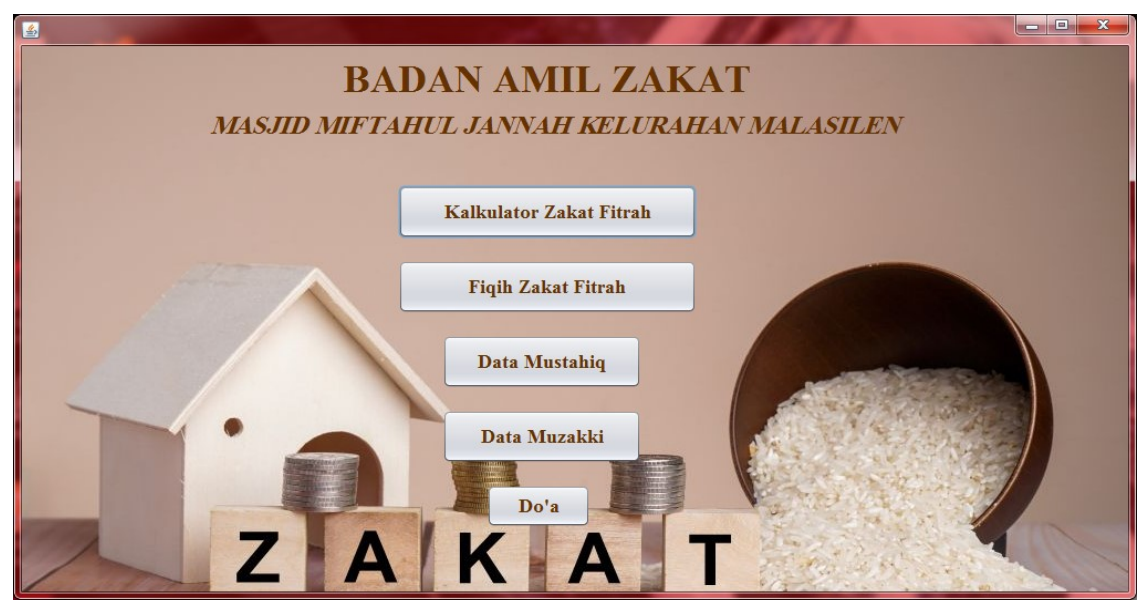

Gambar.3 Menu Utama Sistem Pengelolaan Zakat Fitrah

Ujicoba yang dilakukan untuk mengukur kelayakan sistem informasi pengelolaan zakat fitrah pada BAZ Masjid Miftahul Jannah yang telah di rancang menggunakan pengujian blackbox. Pengujian blackbox dilakukan dengan menilai seluruh fungsional. Metode pengujian menekankan pada menjalankan fungsi dan pemeriksaan input dan data output dari sistem informasi pengelolaan zakat fitrah pada BAZ Masjid Miftahul Jannah di Kelurahana Malasilen. Fungsi, input dan data output tersebut adalah layout menu utama, layout menu kalkulator zakat fitrah, layout menu fiqih zakat fitrah, layout menu data Mustahiq dan Muzakki, juga menu layout Do'a. Setelah melalui proses pengujian blackbox oleh ahli sistem berikutnya ujicoba akan di lakukan dengan melakukan validasi sistem informasi pengelolaan zakat fitrah berbasis J2SE terhadap ahli serta pengujian langsung oleh pengguna dengan skala besar minimal 30 orang responden.

Pengujian blackbox dilakukan memiliki beberapa komponen yang akan diujikan. Komponen yang diujikan adalah fungsional, input dan data output tersebut adalah layout menu utama, layout menu kalkulator zakat fitrah, layout menu fiqih zakat fitrah, layout menu data Mustahiq dan Muzakki, juga menu layout Do'a. Rangkuman hasil pengujian blackbox dapat di lihat pada Tabel 1

Tabel.1 Pengujian blackbox

\begin{tabular}{|c|c|c|c|c|c|}
\hline \multirow[t]{2}{*}{ No. } & \multirow[t]{2}{*}{ Rancangan proses } & \multirow{2}{*}{\multicolumn{2}{|c|}{ Hasil yang diharapkan }} & \multicolumn{2}{|c|}{ Kriteria } \\
\hline & & & & Ya & Tidak \\
\hline \multirow[t]{7}{*}{1.} & Klik Menu Kalkulator & 1 . & Masuk Pada Menu & $\mathrm{Ya}$ & \\
\hline & Zakat Fitrah & & Kalkulator Zakat & & \\
\hline & & 2 . & Dapat Input Besaran Zakat & $\mathrm{Ya}$ & \\
\hline & & & Fitrah & & \\
\hline & & 3. & Dapat Input Banyaknya & $\mathrm{Ya}$ & \\
\hline & & & Orang yang Berzakat & & \\
\hline & & & (Muzakki) & & \\
\hline
\end{tabular}




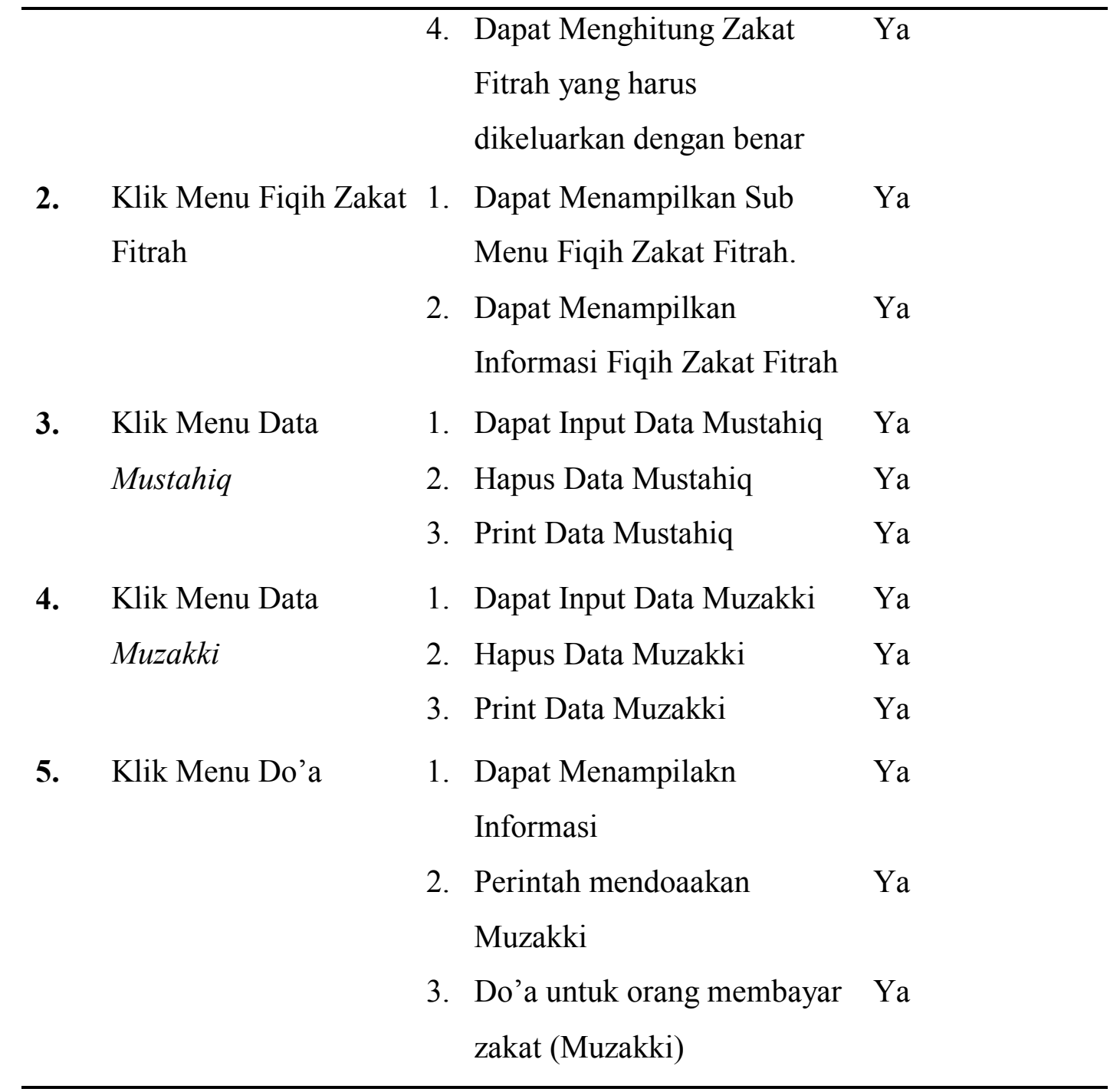

Ujicoba skala besar di lakukan kepada jamaah dan BPH Masjid Mififtahul Jannah di Kelurahan Malasilen berjumlah 15 responden ditambah dengan 15 responden dari berbagai kalangan sehingga jumlah responden keseluruhan berjumlah 30 orang yang bersedia melakukan ujicoba sistem informasi pengelolaan zakat fitrah pada link yang telah disebar melalui media sosial di antaranya whatsapp. Ujicoba yang dilakukan akan mengukur 2 indikator yaitu aspek tampilan, dan aspek penggunaan. Pengujian aplikasi dilakukan dengan mencoba seluruh fungsi serta proses input dan output pada kalkulator zakat fitrah, data mustahiq dan muzakki juga mengujicoba semua fitur-fitur lain sistem pengelolaan zakat fitrah tersebut. Dalam pengujian skala besar ini peneliti mendapatkan 30 responden yang diantaranya Jamaah Masjid Miftahul Jannah, BAZ Masjid Miftahul Jannah, serta dari berbagai unsur masyarakat.

Aspek tampilan yang akan dinilai oleh responden memiliki 10 poin penilaian yang meliputi penilaian mengenai seluruh aspek tampilan yaitu teks, gambar, tombol dan warna. Berdasarkan penilaian ujicoba kelompok besar pada aspek tampilan menghasilkan predikat sangat baik dengan rata-rata setiap poinnya bernilai 3,5 dengan presentase $88 \%$, dengan hasil yang telah didapat dapat disimpulkan bahwa sistem informasi pengelolaan zakat fitrah pada aspek tampilan sangat baik dan layak digunakan BAZ Masjid Miftahul Jannah Kelurahan Malasilen. 
Aspek penggunaan memiliki 11 poin penilaian yang akan di nilai oleh responden, aspek penggunaan yang akan di nilai adalah aspek penggunaan sistem informasi dan menghasilkan predikat sangat baik dimana rata-rata penilaian 3,6 dengan presentase $90 \%$ sehingga dalam aspek penggunaan dapat disimpulkan bahwa Sistem Pengelolaan Zakat Fitrah sangat baik dan dapat digunakan pada BAZ Masjid Fiftahul Jannah Kelurahan Malasilen.

\section{Kesimpulan}

Berdasarkan hasil penelitian merancang sebuah aplikasi sistem informasi pengelolaan zakat fitrah pada BAZ Masjid Miftahul Jannah di Kelurahan Malasilen dengan menggunakan Java Netbeans penulis berhasil merancang aplikasi sistem informasi pengelolaan zakat fitrah berbasis J2SE (Java Platform Standard Edition) dengan baik. Dalam pengujian ujicoba kelompok besar yang dilakukan kepada 30 responden, aplikasi sistem informasi pengelolaan zakat fitrah berbasis J2SE (Java Platform Standard Edition) memiliki penilaian dengan presentase $88 \%$ untuk aspek tampilan, $89 \%$ untuk aspek penggunaan dengan hasil yang sangat baik

\section{Daftar Pustaka}

Abdurahman, H., Riswaya, A. R., \& Id, A. (2014). Aplikasi Pinjaman Pembayaran Secara Kredit Pada Bank Yudha Bhakti. Aplikasi Pinjaman Pembayaran Secara Kredit Pada Bank Yudha BHakti, 8(2), 61-69. http://jurnal.stmikmi.ac.id/index.php/jcb/article/view/114/138

Barri, M. W. H., Lumenta, A. S. M., Wowor, A., \& Elektro-ft, J. T. (2015). Perancangan Aplikasi SMS GATEWAY Untuk Pembuatan Kartu Perpustakaan di Fakultas Teknik Unsrat. 23-28.

Bruno, L. (2013). Panduan Zakat Praktis. Depag, 53(9), 1689-1699. https://doi.org/10.1017/CBO9781107415324.004

Dwiastiti, S., Pendidikan, J., Biasa, L., Dwiastiti, S., Biasa, P. L., Pendidikan, F. I., \& Surabaya, U. N. (2018). DENGAN ALAT HITUNG DIGITAL BAGI SISWA AUTIS Diajukan kepada Universitas Negeri Surabaya untuk Memenuhi Persyaratan Penyelesaian Oleh: DENGAN ALAT HITUNG DIGITAL BAGI SISWA AUTIS. 1-16.

Fendi Nurcahyono. (2012). Pembangunan Aplikasi Penjualan Dan Stok Barang Pada Toko Nuansa Elektronik Pacitan. Sentra Penelitian Engineering Dan Edukasi, 4(3), 15-19.

Fridayanthie, E., \& Charter, J. (2016). Rancang Bangun Sistem Informasi Simpan Pinjam Karyawan Menggunakan Metode Object Oriented Programming (Studi Kasus: Pt. Arta Buana Sakti Tangerang). None, 13(2), 63-70.

Hanafi. (2017). Konsep Penelitian R \& D Dalam Bidang Pendidikan. Saintifika Islamica: Jurnal Kajian Keislaman, 4(2), 129-150.

Ii, B. A. B., Zakat, A. P., Zakat, H., \& Zakat, P. (2002). Didin Hafhiduddin, Zakat dalam Perekonomian Modern, Jakarta: Gema Insani Press, 2002, hlm. 7. 31 17. 17-43.

Jaya, T. S. (2018). Pengujian Aplikasi dengan Metode Blackbox Testing Boundary Value Analysis (Studi Kasus: Kantor Digital Politeknik Negeri Lampung). Jurnal Informatika Pengembangan IT (JPIT), 3(2), 45-48. https://doi.org/10.30591/jpit.v3i1.647

M. Komarudin. (2016). Pengujian perangkat Lunak metode Black box berbasis partitions pada aplikasi sistem informasi di sekolah. Jurnal Mikrotik, o6(3), 02-16. https://doi.org/http://dx.doi.org/10.1016/j.brat.2012.09.004 
Nurudin, M., Jayanti, W., Saputro, R. D., Saputra, M. P., \& Yulianti, Y. (2019). Pengujian Black Box pada Aplikasi Penjualan Berbasis Web Menggunakan Teknik Boundary Value Analysis. Jurnal Informatika Universitas Pamulang, 4(4), 143. https://doi.org/10.32493/informatika.v4i4.3841

Purnomo, D. (2017). Model Prototyping Pada Pengembangan Sistem Informasi. 2(2), 54-61.

Rossaria, M., \& Susilo, B. (2015). IMPLEMENTASI ALGORITMA PENCOCOKAN STRING KNUTH- MORRIS-PRATT DALAM APLIKASI PENCARIAN DOKUMEN DIGITAL. 3(2), 183-195.

Rouf, A. (2012). Pengujian Perangkat Lunak Dengan Menggunakan Metode White Box dan Back Box. vol $\quad 8$ nol, 1-7. http://www.ejournal.himsya.ac.id/index.php/HIMSYATECH/article/view/28/27

Sucipto, S. (2017). Perancangan Active Database System pada Sistem Informasi Pelayanan Harga Pasar. Intensif, 1(1), 35. https://doi.org/10.29407/intensif.v1i1.562

WARMAN, I., \& RAMDANIANSYAH, R. (2018). ANALISIS PERBANDINGAN KINERJA QUERY DATABASE MANAGEMENT SYSTEM (DBMS) ANTARA MySQL 5.7.16 DAN MARIADB 10.1. Jurnal Teknoif, 6(1), 32-41. https://doi.org/10.21063/jtif.2018.v6.

Cut, J., Dien, N., Durian, N., Palapa, P., \& Lampung, B. (2019). APLIKASI AKUTANSI PERSEDIAAN OBAT PADA KLINIK KANTOR. 2(1), 24-33. 